\title{
Pediatric febrile urinary tract infections: the current state of play
}

Ian K Hewitt ${ }^{1}$ and Giovanni Montini ${ }^{2^{*}}$

\begin{abstract}
Studies undertaken in recent years have improved our understanding regarding the consequences and management of febrile urinary tract infections (UTIs), which are amongst the most common serious bacterial infections in childhood, with renal scarring a frequent outcome.

In the past pyelonephritic scarring of the kidney, often associated with vesico-ureteral reflux (reflux nephropathy) was considered a frequent cause of chronic renal insufficiency in children. Increasing recognition as a consequence of improved antenatal ultrasound, that the majority of these children had congenital renal hypo-dysplasia, has resulted in a number of studies examining treatment strategies and outcomes following UTI.

In recent years there is a developing consensus regarding the need for a less aggressive therapeutic approach with oral as opposed to intravenous antibiotics, and less invasive investigations, cystourethrography in particular, following an uncomplicated first febrile UTI. There does remain a concern that with this newer approach we may be missing a small subgroup of children more prone to develop severe kidney damage as a consequence of pyelonephritis, and in whom some form of intervention may prove beneficial. These concerns have meant that development of a universally accepted diagnostic protocol remains elusive.
\end{abstract}

Febrile urinary tract infections (UTI) have long been considered amongst the most common serious bacterial infections in childhood with renal scarring a frequent outcome [1]. We have recently published a review on this topic, highlighting developments in our understanding as a consequence of research conducted in this field, particularly during the past decade [2].

The recognition of an association between UTI, the presence of vesicoureteral reflux (VUR), and the propensity to develop pyelonephritis with subsequent renal scarring led to the concept of "reflux nephropathy" [3]. This term implied a causal relationship between VUR, kidney infection and subsequent major renal damage. As a consequence aggressive treatment with intravenous antibiotics, followed by extensive investigation, initially with urography, later with ultrasound (US) and radionucleotide scintigraphy to detect renal scarring, as well as voiding cystourethrography (VCUG) to detect and grade VUR, was strongly encouraged [4]. Furthermore, children with VUR were advised to commence long term

\footnotetext{
* Correspondence: giovanni.montini@aosp.bo.it

2Department of Pediatrics, Azienda Ospedaliero-Universitaria Sant'OrsolaMalpighi Bologna, Italy

Full list of author information is available at the end of the article
}

antibiotic prophylaxis or undergo surgical correction of the reflux [5].

More recently, assumptions inherent in the above approach to UTIs have been questioned. Large registries, documenting progression to end-stage kidney disease, failed to show any reduction in the incidence or frequency as a consequence of aggressive investigation and management of UTIs [6]. Improved antenatal US has led to the recognition that congenital abnormalities of the kidneys and urinary tract (CAKUT), hypo-dysplasia with or without VUR in particular, is more significant than acquired pyelonephritic scarring as a causative factor for chronic renal insufficiency [7].

In recent years, a number of important prospective clinical trials have improved our understanding, and led us to critically evaluate previous clinical interventions and subsequent investigative protocols.

Studies conducted in infants and young children with uncomplicated febrile UTIs, demonstrated oral antibiotics were equally effective as intravenous antibiotics for the treatment of pyelonephritis $[8,9]$. There was no significant difference in the time to defervescence or rates of subsequent renal scarring. This allows the potential for considerable cost savings.

\section{Biomed Central}


Antibiotic prophylaxis, widely administered to prevent recurrent UTIs, particularly in the presence of reflux, was the next to undergo critical appraisal. Four prospective studies involving 899 children with absent or lesser grades of VUR demonstrated similar rates of recurrent UTI in the treatment versus no treatment groups [10-13], with no significant difference in the incidence of late scarring in 2 of the studies [10,13]. The first large scale randomised, placebo controlled trial involving 576 children with absent or any grade of reflux demonstrated a marginal benefit of antibiotic prophylaxis, however required 14 patient years of treatment to prevent one UTI [14]. Recently the Swedish Reflux Study [15] reported on 203 children aged 1 to 2 years with grade IIIIV dilating VUR, who were randomised to antibiotic prophylaxis, surgical correction or observation. A reduced rate of recurrent UTI was found in girls in the treatment groups compared with observation. In addition no scars occurred in girls on prophylaxis, while those following surgical intervention or in observation suffered 13 scars. No treatment benefit was observed in boys.

In these and other prospective studies of febrile UTI with previously healthy kidneys, around 60\% develop pyelonephritis, of whom 10-40\% will have subsequent scarring [2]. The scarring is usually minor, rarely causing a reduction in overall kidney function, with the severity appearing unrelated to the age of the child [16,17].

These and other studies have led to a general consensus regarding the need to temper the investigations following an uncomplicated first febrile UTI. In the past 5 years a range of approaches have been promoted [18-21]. While no agreement as to an optimal diagnostic protocol exists, there has been a shift away from invasive procedures and those with a substantial radiation burden. In particular, the need to detect all but the few cases of high grade dilating VUR has been questioned, leading to a marked reduction in the number of VCUGs performed. Ultrasound remains widely recommended as a safe non-invasive procedure, however the widespread use of antenatal US has meant that this modality rarely detects abnormalities that result in the need for intervention, and appears of limited value following a first febrile UTI [22,23]. With an increasing focus on the single adverse long term outcome of renal scarring, radionucleotide scintigraphy employing technetium ${ }^{99}$ dimercaptosuccinic acid (DMSA) scanning has been recommended by some. The scan is conducted either in the acute phase following a UTI to confirm pyelonephritis in which case further follow-up and investigation is advised, the "Top Down" approach [18]; or 6 to 12 months later to confirm the presence of any scarring that might require ongoing review [23].

There remain a number of significant unresolved issues.
The development of a universally accepted diagnostic protocol remains elusive. Such a protocol should detect the very few children at risk of progressive kidney damage, who have the propensity to develop the complications of hypertension, pre-eclampsia and chronic renal insufficiency; at the same time not subjecting the vast majority of otherwise healthy children to invasive, costly and unnecessary interventions.

Many remain concerned that we may be missing a small subgroup of children more prone to develop severe kidney damage as a consequence of pyelonephritis, and in whom some form of intervention may prove beneficial. The possibility that various forms of renal hypo-dysplasia, with and without cystic change, may predispose to severe scarring as a consequence of pyelonephritis has not been critically evaluated. The complex interaction between urinary tract obstruction, dysfunctional voiding, increased bladder pressure profiles and the infection-inflammation process characterising pyelonephritis has long been recognised as a significant issue in progression toward chronic renal insufficiency, with current intervention strategies often palliative at most.

Current research is being undertaken to better understand the genetic predisposition and embryologic mechanisms underlying CAKUT in addition to factors that might further complicate acquired pyelonephritic scarring, such as genes involved in inflammation and fibrosis as well as hypertension [24-27]. Embryologic studies suggest abnormal laterally displaced ureteral budding from the bladder wall may predispose to a dysplastic refluxing ureter that makes contact with a reduced amount of mesenchyme forming a smaller hypo-dysplastic poorly functioning kidney.

Finally future strategies to prevent or ameliorate the kidney damage caused by pyelonephritis need to be explored. A recent publication [28] examining steroid therapy in the acute phase of the infection suggests some benefit as previously reported in animal models [29].

The "never ending story" of febrile UTIs has received a lot of attention in recent times, resulting in change from an aggressive to a more circumspect but also watchful approach to the problem. Physicians should however remain alert to the possible diagnosis of pyelonephritis in febrile children and treat appropriately. Where there are atypical features such as lack of response to appropriate antibiotics, infection with non E. Coli organisms, or recurrent episodes further evaluation is always warranted.

\section{Author details}

'Department of Pediatrics, Princess Margaret Hospital for Children, Perth, Australia. ${ }^{2}$ Department of Pediatrics, Azienda Ospedaliero-Universitaria Sant'Orsola-Malpighi Bologna, Italy. 
Received: 18 October 2011 Accepted: 30 November 2011

Published: 30 November 2011

\section{References}

1. Wald E: Urinary tract infections in infants and children: a comprehensive overview. Curr Opin Pediatr 2004, 16(1):85-8.

2. Montini G, Tullus $K$, Hewitt IK: Febrile Urinary tract infections in children. N Engl J Med 2011, 365:239-50.

3. Bailey RR: The relationship of vesico-ureteric reflux to urinary tract infection and chronic pyelonephritis-reflux nephropathy. Clin Nephrol 1973, 1(3):132-41.

4. Kass EJ, Kernen KM, Carey JM: Paediatric urinary tract infection and the necessity of complete urological imaging. BJU Int 2000, 86(1):94-6.

5. Smellie JM, Barratt TM, Chantler C, Gordon I, Prescod NP, Ransley PG, Woolf AS: Medical versus surgical treatment in children with severe bilateral vesicoureteric reflux and bilateral nephropathy: a randomised trial. Lancet 2001, 357(9265):1329-33.

6. Craig JC, Irwig LM, Knight JF, Roy LP: Does treatment of vesicoureteric reflux in childhood prevent end-stage renal disease attributable to reflux nephropathy? Pediatrics 2000, 105:1236-1241.

7. Ardissino G, Dacco V, Testa S, Bonaudo R, Claris-Appiani A, Taioli E, Marra G, Edefonti A, Sereni F: Epidemiology of chronic renal failure in children: data from the ItalKid project. Pediatrics 2003, 111(4 Pt 1):e382-7.

8. Hoberman A, Wald ER, Hickey RW, Baskin M, Charron M, Majd M, Kearney DH, Reynolds EA, Ruley J, Janosky JE: Oral versus initial intravenous therapy for urinary tract infections in young febrile children. Pediatrics 1999, 104(1 Pt 1):79-86.

9. Montini G, Toffolo A, Zucchetta P, Dall'Amico R, Gobber D, Calderan A, Maschio F, Pavanello L, Molinari PP, Scorrano D, Zanchetta S, Cassar W, Brisotto P, Corsini A, Sartori S, Da Dalt L, Murer L, Zacchello G: Antibiotic treatment for pyelonephritis in children: multicentre randomised controlled non-inferiority trial. BMJ 2007, 335(7616):386

10. Garin EH, Olavarria F, Garcia Nieto V, Valenciano B, Campos A, Young L: Clinical significance of primary vesicoureteral reflux and urinary antibiotic prophylaxis after acute pyelonephritis: a multicenter, randomized, controlled study. Pediatrics 2006, 117:626-32.

11. Roussey-Kesler G, Gadjos V, Idres N, et al: Antibiotic prophylaxis for the prevention of recurrent urinary tract infection in children with low grade vesicoureteral reflux: results from a prospective randomized study. J Urol 2008, 179:674-9.

12. Pennesi $M$, Travan $L$, Peratoner $L$, et al: Is antibiotic prophylaxis in children with vesicoureteral reflux effective in preventing pyelonephritis and renal scars? A randomized, controlled trial. Pediatrics 2008, 121:e1489-94.

13. Montini $G$, Rigon $L$, Zucchetta $P$, et al: Prophylaxis after first febrile urinary tract infection in children? A multicenter, randomized, controlled, non inferiority trial. Pediatrics 2008, 122:1064-71.

14. Craig JC, Simpson JM, Williams GJ, et al: Antibiotic prophylaxis and recurrent urinary tract infection in children. N Engl J Med 2009, 361:1748-59.

15. Brandström P, Esbjörner E, Herthelius M, Swerkersson S, Jodal U, Hansson S: The Swedish reflux trial in children: III. Urinary tract infection pattern. $J$ Urol 2010, 184:286-91.

16. Benador D, Benador N, Slosman D, Mermillod B, Girardin E: Are younger children at highest risk of renal sequelae after pyelonephritis? Lancet 1997, 349:17-9.

17. Hewitt IK, Zucchetta P, Rigon L, Maschio F, Molinari PP, Tomasi L, Toffolo A, Pavanello L, Crivellaro C, Bellato S, Montini G: Early treatment of acute pyelonephritis in children fails to reduce renal scarring: data from the Italian Renal Infection Study Trials. Pediatrics 2008, 122:486-90.

18. Preda I, Jodal U, Sixt R, Stokland E, Hansson S: Normal dimercaptosuccinic acid scintigraphy makes voiding cystourethrography unnecessary after urinary tract infection. J Pediatr 2007, 151:581-4, 4 e1.

19. National Institute for Health and Clinical Excellence: Urinary tract infection in children: diagnosis, treatment and long-term management 2007. [http://www.nice.org.uk/nicemedia/pdf/CG54fullguideline.pdf].

20. Subcommittee on urinary tract infection, steering committee on quality improvement and management: Urinary Tract Infection: Clinical Practice Guideline for the Diagnosis and Management of the Initial UTI in Febrile Infants and Children 2 to 24 Months. Pediatrics 2011.

21. Le infezioni febbrili delle vie urinarie: Raccomandazioni di consenso per la diagnosi, il trattamento e il follow-up in bambini di età compresa fra 2 mesi e 3 anni. A cura di un gruppo di lavoro della società italiana di nefrologia pediatrica (SINP).[http://www.sinp.eu/lineeguida].

22. Hoberman A, Charron M, Hickey RW, Baskin M, Kearney DH, Wald ER: Imaging studies after a first febrile urinary tract infection in young children. N Engl J Med 2003, 348:195-202.

23. Montini G, Zucchetta P, Tomasi L, Talenti E, Rigamonti W, Picco G, Ballan A, Zucchini A, Serra L, Canella V, Gheno M, Venturoli A, Ranieri M, Caddia V,

Carasi C, Dall'Amico R, Hewitt IK: The value of imaging studies following a first febrile urinary tract infection I in young children: data from the IRIS1 trial. Pediatrics 2009, 123:e239-46.

24. Ichikawa I, Kuwayama F, Pope JC IV, Stephens FD, Miyazaki Y: Kidney International Paradigm shift from classic anatomic theories to contemporary cell biological views of CAKUT. Kidney Int 2002, 61:889-898.

25. Winyard P, Chitty LS: Dysplastic kidneys. Semin Fetal Neonatal Med 2008, 13:142-151.

26. La Scola C, Hewitt I, Pasini A, Pugliese F, Montini G: Postnatal management of congenital bilateral renal hypodysplasia. J Matern Fetal Neonatal Med 2010, 23(Suppl 3):97-100.

27. Woolf AS, Price KL, Scambler PJ, Winyard PJ: Evolving concepts in human renal dysplasia. J Am Soc Nephrol 2004, 15:998-1007.

28. Huang YY, Chen MJ, Chiu NT, Chou HH, Lin KY, Chiou YY: Adjunctive oral methylprednisolone in pediatric acute pyelonephritis alleviates renal scarring. Pediatrics 2011, 128:3, e496-e504.

29. Pohl HD, Rushton HG, Park JS, Chandra R, Majd M: Adjunctive oral corticosteroids reduce renal scarring: the piglet model of reflux and acute experimental pyelonephritis. J Urol 1999, 162:815-20.

doi:10.1186/1824-7288-37-57

Cite this article as: Hewitt and Montini: Pediatric febrile urinary tract infections: the current state of play. Italian Journal of Pediatrics 2011 37:57.

\section{Submit your next manuscript to BioMed Central and take full advantage of:}

- Convenient online submission

- Thorough peer review

- No space constraints or color figure charges

- Immediate publication on acceptance

- Inclusion in PubMed, CAS, Scopus and Google Scholar

- Research which is freely available for redistribution

Submit your manuscript at www.biomedcentral.com/submit
C Biomed Central 